\title{
Psychological Responses of Patients Receiving a Diagnosis of Adenocarcinoma
}

\author{
Rabia Haddad RN, MSN, CNS-PMHN* \\ King Abdullah University Hospital, Jordan University of Science and Technology, Irbid, Jordan
}

${ }^{\star}$ Corresponding author: Rabia Haddad RN, MSN, CNS-PMHN, King Abdullah University Hospital, Jordan University of Science and Technology, Irbid, Jordan; E-mail: Rabiahaddad200@yahoo.com

Received: May 06, 2021; Accepted: May 12, 2021; Published: May 20, 2021

Mr. X is a 62-year-old man who just had a needle biopsy of the pancreas showing adenocarcinoma. The nurse and his doctor want to tell the patient about this result?

\section{Question One}

How can you deliver this news to Mr. X (Refer to 2 articles, references?)

\section{Answer}

In some health organizations, the patients kept ignored in relation to the true nature of their disease, the risks involved, and their prognosis. While in some cases a doctor and a nurse may still withhold information concerning certain details that might threaten the recovery of a patient who is unstable, nervous, or seriously depressed. Nowadays, the sharing of information is governed by the principle of autonomy that is, patients themselves take decisions on everything concerning their disease and must confirm their knowledge and acceptance of any tests or treatments that carry risks by signing an informed consent form Guerra-Tapia [1]. Therefore, before starting to discuss the case of Mr. X and how to inform him with his new diagnosis, more emphasis should be done to understand the definition of what we call it as "bad news". Buckman (1984) [2], was the first person to define the bad news as "any information likely to alter drastically a patient's view of his or her future" [3]. Although those information are as it was mentioned in the definition will altered Mr. X expectations for his future, he should be informed about his condition. Delivering unfavorable information is important for many reasons. Giving him the truthful and correct information about his condition can help him make informed choices about his treatment and take responsibility for his care, rise his understanding and awareness of his condition and support him to make appropriate plans for his future. Additionally, this practice will prevent him from undertaking heavy treatment and facilitate end-of-life care planning [4]. Mr. X should know everything he needs in order to participate in diagnostic and therapeutic decisions concerning his own disease. As a long term outcome, Mr. X will perceive the healthcare team as honest; he will experience an increase in his satisfaction, compliance, and coping mechanisms. Moreover, and in general, after a person's death, memories of care at the end of life will remain with those who grieve the loss and can affect their perception of the facility, healthcare professionals, or memories about their role in easing suffering or death. For these reasons, bad news must be delivered sympathetically and empathetically [4].

\section{The Barriers to Break the Bad News}

On the other hand, and in order to decrease the barriers of breaking the bad news, we as a health team members should establish Mr. X's trust and rapport, reduce his anxiety and uncertainty, educate him, provide him with the sufficient support, and help him to establish a treatment plan. All of those points will be enhanced and supported by the usage of proper communication skills which can be the most important tool we have to support Mr. X and his family on their cancer journey. Yet, oncology nurses may find communicating bad news difficult for several reasons. One of those reasons is that the nurses may fear that sharing critical medical information can cause harm, such as hopelessness, depression, or a sense of disappointment to the patient. Other reason is that, delivering bad news can be painful because of nurses' lack of practice or skill; embarrassment with emotional reactions, such as denial or anger that can be focused toward care providers; or fear of removing hope. Further reasons are related to the staff overload, not finding the right time to talk to the patient and the increase in hospital unit demanding. Even during the pressured time, the nurses should be aware of their tone of voice, facial expressions, hand gestures, posture of being unhurried, and attention to space and touch. In addition to all of those reasons, lack of special training in breaking the bad news and how to deal with cancer patients is another crucial issue. Extra barriers encountered by both physicians and nurses include concerns about lack of privacy, language and cultural barriers and inconsistencies between relatives' and patients' wishes as to whether information is withheld or shared [5].

\section{The Role of the Nurse in Breaking the Bad News}

Communicating the bad news for the patient is not conserved only by the physician; in contrast, it is a multidisciplinary activity which necessitates the active participation of a wide range of healthcare professionals working as a team. The nurse actually became actively involved in the process of breaking bad news by assuming the role of educator, supporter, and advocate for patients. They were also involved in the bad news process as they helped patients understand the implications of their illnesses. The supportive 
activities that nurses have been found to engage in around bad news include assessing needs for information, identifying and clarifying misunderstandings, initiating discussion, obtaining and explaining complex medical information and helping patients and relatives cope with their emotional reactions [6]. Once news has been given, nurses often are asked additional questions about bad news after the physician leaves the room and may be needed to help restore equilibrium with patients or family members. Warnock et al. [4] did a study about "breaking bad news in in-patient clinical settings: role of the nurse". They concluded that guidance for breaking bad news should encompass the whole process of doing this and acknowledge the challenges nurses face in the inpatient clinical area. Developments in education and support are required that reflect the challenges that nurses encounter in the inpatient care setting. From this study we can conclude that, nurses should have a vital role in breaking the bad news but after appropriate and high quality training sessions on the steps or strategies for delivering the bad news. Moreover, nurses can deliver hope and serve as advocates for patients and families by sharing patients' information needs or concerns with the healthcare team and physician, providing support for the physician who may feel guilt or unwillingness to approach unfavorable issues, meeting with patients and families afterward to comfort them and clarify issues, and presenting information in the context of patients' hopes and expectations [5].

\section{The Steps for Delivering the Bad News to Mr. X}

Delivering the bad news can be perceived as a process, which includes the communications that take place before, during and after the moment that bad news is delivered. Therefore, the preparation of Mr. X and /or his family for receiving the bad news, clarification and explanation for the information they have been given during all the disease stages become part of the process. Radziewicz [5], describe the skills for breaking the bad news by using the SPIKES-Six Step Protocol which was developed in 2000 by Baile [7] and colleagues. This model includes six steps: Setting, Perception, Invitation, Knowledge, Emotion, and Summary. But according to Guerra (2013) [1], they used what they called it as five practical steps that actually have the same concepts or way of approach to the SPIKES but without labeling the steps. They also add four pre-conditions criteria which should be met before breaking the bad news. Thus, and in the situation of Mr. $\mathrm{X}$ who was newly diagnosed with adenocarcinoma, we as a physician and a nurse (health team members) start to break the bad news in such a way: First we have to meet the four pre-conditions. Me and the physician should set first together and evaluate the seriousness of Mr. X disease and its prognosis, so we will understand the case from all the angles. Also, we should remember that each patient is a unique individual, and Mr. X is having a different personality, work situation, and Religious beliefs, economic status than the other patients. Then, we should know which type o family $\mathrm{Mr}$. $\mathrm{X}$ is belonging to? If he likes to involve his family in the discussion of the bad news? And whom he wants to include in the meetings? The last consideration that, we as a group should foster the trust relationship between us and Mr. X. choosing the right members in our team who dealt previously with Mr. X and know him well will facilitate the delivery of his bad news. As a first practical step in delivering the bad news is to analyze the context. In this step, we should prepare ourselves by considering the questions of when, how, with whom, and how long to take with Mr. X. The context or the environment where the interview will be held in should be chosen precisely (e.g., free from distractions and interruptions, has a comfortable chairs, closed enough to maintain Mr. X privacy, and free enough for a reasonable length of time). The second step is to consider the starting point. This will include questions like: what does Mr. X know? What does he want to know? We should provide the answers and must accept possible silences, evasive answers, or a refusal to be informed, but always offer another possibility. Sharing the information is the third step in breaking the bad news. For this, we must do the following three points: firstly, pay attention to nonverbal communication (gestures, postures, looks). We should look to Mr. X directly in his eyes, but we must be careful not to stare, as that might frighten him. Our facial expression should express seriousness, but not severity. Gestures should be kind, but not overly cheerful. We should speak in a neutral tone, with a firm voice that is neither authoritarian nor tremulous. Our manner should express confidence and be unhurried. We also need to be prepared for the possibility when Mr. X taking his anger out on us, following the impulse to "kill the messenger". The best response will be a serene and understanding one. Secondly, pay attention to verbal communication (the words). The most important elements here are our opening words, in which we formulate our main statements, questions, and answers. We must present the facts as objectively and concretely as possible. Difficult expressions and technical terminologies should be avoided, unless we are going to clarify their meaning immediately. During the interview, comprehension should be checked regularly: "Do you understand what I mean?". Lastly, listen attentively to Mr. X feelings even if he interrupts our explanations. Listen with an attitude that is not judgmental or moralizing. Listening in this way, even to the silences, is known as "active listening" and is a very effective tool in human communication Guerra [1]. The fourth step in bad news breaking is to empathize, don't sympathize. We as a breaking the bad news team must try to imagine how the other person might feel without letting it affect us personally. It is good to be well practiced in giving support and to learn to empathize with our patients' emotions without identifying with their anguish. Repeated failure in adapting to individual situations can lead to physician and nurse burnout. The fifth and last step is that propose care and follow-up for Mr. X. We cannot change bad news, but we can offer positive advice and constant emotional support both to Mr. X and to his family. There is always something that can be done (e.g., "We can start eliminating the affected areas"). We should try to manage uncertainty without setting specific time limits. Additionally, we can reinforce the role of the family as a resource of support and provide information about the social support available from support groups, patients' associations Guerra [1]

\section{Question Two}

Mr. X is crying uncontrollably. The nurse helps the client to calm down and then asks what made him cry. Mr. X says (I’m feeling very guilty). When the nurse ask why, Mr. X suddenly stops crying and replies angrily (why do you think I've been keeping quiet? I know you will tell everybody here about what a failure I am. Please leave me 
alone. I'm not saying anything. How will the nurse earn Mr. X trust to help build a therapeutic relationship? Refer to 2 articles.

\section{Answer}

Trust is described as a belief that our good will be taken care of, or as an attitude bound to time and space in which one relies with confidence on someone or something, and as a willingness to engage oneself in a relationship with an acceptance that vulnerability may arise [8]. Also it defines as "rely on "or "confidence in truth [9]. Although concept of trust is used in everyday nursing language, but it's still vague, complex and not fully understood among nurses [10] conducted a systematic review to identify empirical studies on trust within the nurse-patient relationship and to analyze and synthesize the results, a total of thirty four studies were included, twenty-two studies used a qualitative design, and twelve studies used quantitative research methods. The context of most quantitative studies was nurse caring behaviors, whereas most qualitative studies focused on trust in the nurse-patient relationship, the result revealed that building trust was characterized as a process that includes various stages during which trust could be established, damaged and repaired, the first characteristic, trust is a dynamic process which means that it is ongoing process from feeling comfortable to building a rapport, that cannot be hastened. The trust-building process between nurse and patients involved trying to understand each other, individualizing and sharing of self, and for patients with chronic illness, the process developed from general naïve trust into specific reconstructed trust. The second characteristic trust as a relational phenomenon, which means trust was regarded as the foundation of any therapeutic relationship, and an essential element of nurse-patient relationships, It is considered inherent in the relationship between a nurse and children and between a nurse and parents, establishing a trusting relationship with patients was identified as an important facet of the nurse's role and as a basis for continued care and treatment. Also trust is not something that nurses possess or are given; instead, it is something that they earn and have to work hard to achieve. It requires a two-way relationship between the person who makes themselves trustworthy and the person who puts their trust in them. Third characteristic trust as a fragile and ambiguous phenomenon, trust and distrust are often viewed as two ends of a continuum, and exposed as "fragile " phenomena that can easily " tip over" towards their opposites. Also the findings of included studies indicated that various factors may facilitate or impede the development of a trusting relationship, some of which were related to personal and professional characteristics of nurses or vulnerability of patients. Factors that facilitate the trust such as accepting patient's culture and life style, and decisions without prejudgment, providing good advice, convey respect, show warmth and caring, use active listening, give sufficient time to answer patient's questions, maintain confidentiality, show congruence between verbal and nonverbal behaviors, use appropriate eye contact, give complete information, provide consistency, be honest and open. Factors that hinder trust such as is lack of the necessary knowledge and skill to undertake nursing procedures, using medical terminology or jargon which the patient does not fully understand creates a language barrier that hinders effective communication and the building of a trusting relationship. Additionally, failure to anticipate or understand the information needs of patients, depersonalizing the patient by referring to him or her by medical diagnosis or bed number, neglecting responsibilities and remaining distant undermined patients' trust of nurses, also work-related factors and emotionally challenging nursing procedures such as busy workload, inadequate time, lack of parental understanding. Similarly Hillen [11-16] designed a systematic review to describe the current knowledge of the conceptualization, assessment, correlates, and consequences of cancer patients' trust in their physician, a total of eleven studies were included, and the result revealed that trust in physicians was strong overall, patients' trust appeared to be enhanced by the physician's perceived technical competence, honesty, and patient-centered behavior. A trusting relationship between patient and physician resulted in facilitated communication and medical decision making, a decrease of patient fear, and better treatment adherence. So after discussing these articles we can answer this question as: the nurse can earn Mr. X trust by firstly, telling him the truth and use honest disclosure related his condition and treatment option with full honesty and clarity, upon clarifying Mr. X diagnosis and prognosis and the treatment option, secondly, speaking with good purposes and calm approaches with honest, clear and respectful ways of communication that will contribute to building our relationship with Mr. X. thirdly, telling him about his diagnosis and prognosis and that all the issues related to his condition will be confidential; by stating that "Mr. X keep in mind that all information related to your health condition will be confidential", fourthly, providing alternatives regarding his condition and his diagnosis with adenocarcinoma, then allow for decision making, in this stage we empower the patient by providing alternatives and allow him to choose, acknowledge Mr. X skills and abilities and demonstrates respect for his decisions and choice in the previous stage of communication. Fifthly, manage expectation and make it realistic and explicit, also to clarify the limits and boundaries of what can be done to treat his cancer, establishing therapeutics and professional boundaries, clear boundaries allow for safe and a therapeutic connection between the nurses and Mr. X. sixthly, using therapeutic ways of communication such as showing empathy, giving information, and exploring to answer and to build therapeutic relationship with Mr. X. Finally, building trust is an ongoing and progressive process during all phases of working with Mr. X.

\section{Question Three}

The nurse can provide Mr. X with the names and details of other clients in the unit who have been through similar experiences to make him realize that he is not the only one who have such diagnosis?

\section{A: True \\ B: False}

Select true or false and rationalize your answer?

\section{Answer}

False; the nurse at Mr. X situation breaches the principle of confidentiality when she shares information for other patient without the patient approval. The nurse should protect health information; including: Names, Geographic data, All elements of dates, Telephone numbers, and any information that can be used to identify the individual. Also Mr. X may feel insecure about his information and privacy, when the information of other patient shared to him. 


\section{Question Four}

Connection with its corresponding:

Answer in the table below (Table 1):

Table 1: Answers to Question 4.

\begin{tabular}{|l|l|l|}
\hline Num & Element & Description \\
\hline 1 & Trust & Involve talking the risk of sharing oneself with another \\
\hline 2 & Professionalism & $\begin{array}{l}\text { Involve applying a specific background of knowledge } \\
\text { and skills }\end{array}$ \\
\hline 3 & Genuineness & $\begin{array}{l}\text { Allows the nurse to relax and resist trying to impress } \\
\text { others }\end{array}$ \\
\hline 4 & Empathy & $\begin{array}{l}\text { Having insight into the meaning of the other persons } \\
\text { thoughts, feeling and behaviors }\end{array}$ \\
\hline 5 & $\begin{array}{l}\text { Unconditional positive } \\
\text { regard }\end{array}$ & $\begin{array}{l}\text { Respecting and being attentive regardless of the other } \\
\text { persons behavior }\end{array}$ \\
\hline 6 & Caring & $\begin{array}{l}\text { Meeting a client needs and providing comfort measure } \\
\text { when required }\end{array}$ \\
\hline
\end{tabular}

\section{References}

1. Guerra Tapia A, González Guerrab E (2013) Communicating Bad News During an Office Visit: Transmisión de malas noticias en la consulta. Actas Dermosifiliogr 104: 1-3.

2. Buckman R (1984) Breaking bad news: why is it still so difficult? BMJ 288: 1597-1599. [crossref]

3. Martins RG, Carvalho IP (2013) Breaking bad news: Patients' preferences and health locus of control. Patient Education and Counseling 92: 67-73. [crossref]

4. Warnock C, Tod A, Foster J, Soreny C (2010) Breaking bad news in inpatient clinical settings: role of the nurse. Journal of Advanced Nursing, 66: 1543-1555. [crossref]
5. Radziewicz R, Baile FW (2001) Communication Skills: Breaking Bad News inthe Clinical Setting. Leadership and Professional Development 28: 951-953. [crossref]

6. McSteen K, Peden-McAlpine C (2006) The role of the nurse as advocate in ethically difficult care situations with dying patients. Journal of Hospice and Palliative Nursing 8: 259-269.

7. Back AL, Arnold RM, Baile WF, Tulsky J A, Fryer-Edwards K (2005) Approaching Difficult Communication Tasks in Oncologyl. CA: A Cancer Journal for Clinicians 55: 164-177. [crossref]

8. Dinç L, Gastmans C (2012) Trust and trustworthiness in nursing: an argument-based literature review. Nursing inquiry 19: 223-237. [crossref]

9. Bell L, Duffy A (2009) A concept analysis of nurse-patient trust. British journal of Nursing 18: 46-51. [crossref]

10. Dinç L, Gastmans C (2013) Trust in nurse-patient relationships: a literature review. Nursing ethics 20: 501-516. [crossref]

11. Hillen MA, de Haes HC, Smets EM (2010) Cancer patients' trust in their physician-a review. Psycho-Oncology 20: 227-241. [crossref]

12. Dean E (2011) It's not all bad news: how the care campaign challenges are being met. Nursing Standard 26: 12-13.

13. Kaplan M (2010) SPIKES: a framework for breaking bad news to patients with cancer. Clinical Journal of Oncology Nursing 14: 514-516. [crossref]

14. Konstantis A, Exiara, T. (2015) Breaking bad news in cancer patients. Indian Journal of Palliative Care 21: 35-38. [crossref]

15. McGowan C (2012. Patients' confidentiality. Critical Care Nurse 32: 61-64.

16. Salem A, Salem AF (2013) Breaking Bad News: Current Prospective and Practical Guideline for Muslim Countries. Journal of Cancer Education 28: 790-794. [crossref]

\section{Citation:}

Haddad R (2021) Psychological Responses of Patients Receiving a Diagnosis of Adenocarcinoma. Cancer Stud Ther J Volume 6(2): 1-4. 